18, 1947. The latter, therefore, undoubtedly have developed from larvæ occurring in Dutch waters.

Rijksmuseum van Natuurlijke Historie, H. Воsснма

$$
\text { Leyden. }
$$

2 Jones, E. W. Knight, Nature, 161, 202 (1948).

' Bishop, M. W. H., Nature, 159, 501 (1947).

\section{What is a Dialysate?}

IN Nature of November 22, 1947, p. 720, H. G. Derx has commented upon the confusion caused by the lack of a suitable name for the material retained by a dialysing membrane. He has proposed the use of the term 'residue'. We have found the term 'impermeate', coined by Dr. Howard Eder in our laboratories some years ago, a very descriptive and helpful one to apply to such material

Department of Biological Chemistry,

$$
\text { Erto G. Ball }
$$

Medical School, Harvard University.

\section{Operational Research}

IN spite of the frequency with which operational research has been referred to recently, there are extremely few published discussions from which the layman can obtain an idea of what it is ${ }^{1}$. Its nature is actually extremely straightforward; the very simplicity of the basic idea is probably one of the reasons why many people seem to find it so difficult to grasp. In the first place, operational research is research in the true sense. I would refer to Blackett's obituary notice of E. J. Williams ${ }^{2}$, in which he tells how Williams found the phenomena of U-boat warfare as intellectually enthralling as those of atomic physics; and Williams could scarcely have been accused of not knowing what scientific research really means. The adjective 'operational' does not mean that the activity is not true research, any more than do the adjectives in such expressions as 'chemical research', 'genetical research', etc. It characterizes, not the quality of the research, but its subjectmatter, which was originally the operations of armed forces. In a wider definition, operational research can be described as the application of the methods of scientific research to the study of the problems which face an executive authority.

The special characteristic which differentiates operational research from other branches of applied science is that it takes as the phenomenon to be studied the whole executive problem and not the individual technical parts; its interest may be focused, for example, on 'how to find U-boats from aircraft', while specialist applied sciences would be studying component parts of the situation, such as the physics of radar, the psycho-physiology of fatigue, etc. It is, perhaps, because operational research scientific workers had to depend so largely for detailed information on the generous collaboration of their specialist colleagues that some people appear to think that they invented new techniques of teamwork. How badly the world needs such techniques! But it is for the sociologists, not the operational research workers, to discover them.

In point of fact, operational research possesses no new or special technique of its own. It uses the normal methods of scientific research to discover the facts about the phenomena which it is studying. Naturally, some of science's armoury of methods are more appropriate to its subject-matter than are others, just as genetical research often calls for statistical methods, while experimental embryology finds more use for manipulative skill. But it has no secret weapon.

Why, then, it may be asked, is it important to consider whether sufficient use is being made of operational research during peace? The answer, I think, is that although the methods of operational research are not new, the direct application of those methods to executive problems had only been made very spasmodically before the War, and, when undertaken on a reasonably large scale, proved itself to be extremely fruitful. The Services, which, on the fighting side, have an organisation designed for the specific purpose of deciding what to do and then doing it, soon recognized the difference between analysing the situation (operational research), drawing up a scheme to cope with it (planning) and putting the scheme into effect (operations), and possessed a framework into which the first of these could easily be fitted. The civil branches of government, which have only recently been called upon to initiate and carry out major enterprises, seem to find these distinctions more difficult to grasp; and we find Nature implying that operational research is a method of plannings. Research by itself can never produce a plan; its function is to prepare the basis on which a rational plan can be founded, by identifying qualitatively the factors in the situation, and, as far as possible, by evaluating them quantitatively. It seems to me astonishing that any scientific worker should doubt that the scientific method is by far the most powerful instrument we have for performing the analysis and fact-finding on which executive decisions should be based. Surely no one could be satisfied to try to "re-deploy the scientific effort of Great Britain" without trying first to find what the probable demands are in the various fields; what the available resources are, and would become; how many men of science could function equally well if re-directed into other fields; for what reasons scientific workers have taken up the work they are now doing; what the demands on teaching establishments would be to achieve different rates of redeployment; and so on. Investigations of this nature, which would take into account all the factors which could be shown, or surmised, to influence the situation, would be equally necessary whether the planners eventually decided to put their schemes into effect by a totalitarian fiat, or by any of the gamut of subtler systems of payments and incentives. A beginning should be made with them, even though one believes that the brute facts, like Archimedes' tortoise, can never be completely overtaken by scientific analysis. But it only obscures the issue if consideration of the importance of research on behalf of the executive planners is prejudiced by opinions as to the method by which the plan should be put into operation.

Institute of Animal Genetics,

\section{H. WADDINGTON}

University of Edinburgh. Jan. 15.

2 Joubert, Air Chief Marshal Sir Phillip, "Science and the Statesman", Observer (Dec. 16, 1945). Waddington, C. H. World Review, p. 49 (June 1945), Polemic, No. 4, p. 49 (1946). Kittel, C., Science, 105 Nature, 160, 660 (1947).

Nature, 156, 655 (1945).

- Nature, 161, 1 (1948).

[As Prof. Waddington remarks, there have been few widely available accounts of operational research. The article by Sir Charles Goodeve on p. 377 will help to clarify the situation. EDITors.] 